\title{
Construction Waste Reduction Through BIM-Based Site Management Approach
}

\author{
Burcu Salgın*t, Atacan Akgün*, Nilay Coşgun**, Kofi Agyekum*** \\ *Department of Architecture, Faculty of Architecture, Erciyes University, 38030, Kayseri, Turkey \\ ** Department of Architecture, Faculty of Architecture, Gebze Technical University, 41400, Kocaeli, Turkey \\ *** Department of Building Technology, Kwame Nkrumah University of Science and Technology, Kumasi, Ghana \\ (bsalgin@erciyes.edu.tr, atacan@erciyes.edu.tr, nilaycosgun@gtu.edu.tr, agyekum.kofi1@gmail.com)
}

ॠCorresponding Author; Burcu Salgın, Department of Architecture, Erciyes University, 38030, Kayseri, Turkey

Tel: +90 352437 5282, Fax: +90 352437 6554, bsalgin@erciyes.edu.tr

Received: 22.05.2017 Accepted: 30.08 .2017

\begin{abstract}
Today, construction practices with potential damages to the environment are carried out uncontrollably to respond to the rapidly growing population needs. In the construction sector, which is one of the leading sectors closely following technological developments, steps must be taken to protect the world's ecologic balance. The goal of the professionals is not only to put up a building in accordance with its design but also to comply with environmental requirements in a respectful way. Different parameters such as erroneous design decisions, inadequate work schedules, sudden weather oppositions, defects in product supply can directly or indirectly affect the construction process, resulting in the generation of construction waste on the construction site. These wastes negatively affect the living and non-living environment. It is not technically possible to completely eliminate construction wastes generated during the construction process, but it is possible to control and recover these wastes. For this reason, innovative applications are important in the construction sector. This study examines the potential of BIM applications in preventing/reducing wastes in the construction process. For this purpose; articles that talk about the reasons of waste generation in the construction sector and the relationship between BIM technology and construction waste management practices were examined, and the findings obtained were evaluated. BIM applications are being proposed to be developed to prevent/reduce wastes on the construction site.
\end{abstract}

Keywords C\&D Waste, Building Information Modelling, Construction Site Management

\section{Introduction}

The definition of waste includes all types of materials which exist as solid, liquid or gas, which arise as a result of production and usage activities, and which, when disposed of directly or indirectly, have the potential to harm human health or the natural environment.

Waste may be classified as medical, domestic, industrial, agricultural, mineral and construction \& demolition (C\&D). The various types of wastes may pollute air, water and soil, and may negatively affect the topography of the land. Pollution of the natural environment, such as air, water and soil, has a wide range of negative effects. This may take the form of visual pollution of a landscape, or biological or ecological effects on living organisms, including humans, plants and animals, and may lead to various diseases. Although the primary focus is on addressing the environmental damage caused by such waste streams, they also represent considerable economic losses. In this context, the effective management of these wastes in order to minimize their environmental and economic impacts is one of the most important issues of the 21 st century. This is because waste prevention/reduction is the most beneficial, most economical and most environmentally sustainable approach within the waste management hierarchy. Consumption of natural resources and increasing production of waste require solutions to protect the quality of the natural and built environments. For these solutions to be effective, 
waste management models must be developed and it is important to reduce waste at the source.

Increased construction activities along with the increasing population in the world lead to growing environmental problems, because buildings and the users of buildings generate waste throughout the building life processes (construction, usage and demolition). Various interpretations and definitions of waste can be found in construction waste related literature. The European Waste Framework Directive 2008/98/EC define waste as "any substance or object which the holder discards or intends or is required to discard" [1]. Ekanayake and Ofori [2] defined construction waste as "any material, apart from earth materials, which needs to be transported elsewhere from the construction site or used within the construction site itself for the purpose of land filling, incineration, recycling, reusing or composting, other than the intended specific purpose of the project due to material damage, excess, non-use, or noncompliance with the specifications or being a by-product of the construction process". Mossman [3] defined material waste as anything that is not needed to generate value for the end-user. Waste can also be defined as an excessive use or carelessness of material [4]. Several studies have categorized the major sources of waste on construction sites to include reworks/repairs, defects, material waste, delays, waiting, poor material allocation, and unnecessary material handling $[5,6,7,8,9]$. Waste may also occur as a result of natural disasters like earthquakes and tornadoes. As can be inferred in the definitions, there are several kinds of construction wastes and they occur at different stages of a building's life cycle. To prevent economic and ecological loses, it is important to prevent/reduce construction waste on construction sites. With this aim, many site management strategies are developed all around the world. One of them is using BIM in construction site management. Although it is quite a new approach, it is gradually gaining recognition among construction professionals. This paper is therefore aimed at reviewing literature on the reduction/prevention of construction waste using BIM-based construction site management approach.

\section{Origins of Construction Waste on Site}

This section of the study adopted a similar methodology used by Nagapan et al. [10] to conduct their study. It involved a two-stage methodology which included: identifying the cause of waste generation through literature review and categorization of the major factors. Generally, waste may occur as a result of series of events and may not be due to a remote aspect [11]. Mapping of the factors in Table I gives a preliminary idea on what past researchers had discovered about the factors that contribute to construction waste generation on sites.

Table 1. Causes of waste generation on construction sites identified in literature

\begin{tabular}{|c|c|c|c|c|c|c|c|c|c|c|c|c|c|c|c|}
\hline \multicolumn{2}{|c|}{ Causes of Waste Generation } & 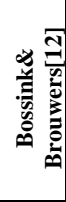 & 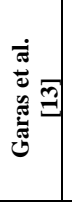 & 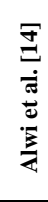 & 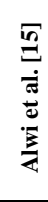 & 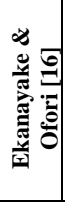 & 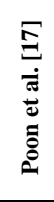 & 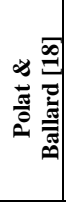 & 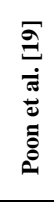 & 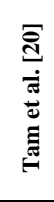 & 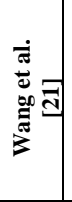 & 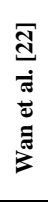 & 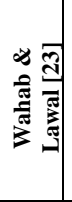 & 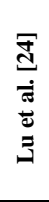 & 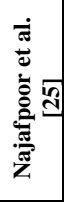 \\
\hline \multirow{6}{*}{ 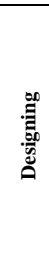 } & Last minute changes & - & - & - & - & - & - & - & - & - & - & - & - & • & \\
\hline & Designers' lack of knowledge & • & $\bullet$ & $\bullet$ & $\bullet$ & $\bullet$ & $\bullet$ & $\bullet$ & & & & & & & \\
\hline & Design errors & $\bullet$ & & $\bullet$ & $\bullet$ & $\bullet$ & & $\bullet$ & & $\bullet$ & & $\bullet$ & & & \\
\hline & Complicated design & & & & & $\bullet$ & $\bullet$ & $\bullet$ & & & & & & & \\
\hline & Poor design quality & & & & - & & & & & & • & & & & \\
\hline & Lack of environmental awareness & & & & & & - & & & & $\bullet$ & & & & \\
\hline \multirow{2}{*}{ 8ิ } & Lack of coordination among parties & & $\bullet$ & & $\bullet$ & & & $\bullet$ & & & & $\bullet$ & & & \\
\hline & Lack of comunication among designers & & $\bullet$ & & & & - & $\bullet$ & & & & & & & \\
\hline \multirow{3}{*}{ 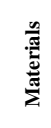 } & Poor material handling & & $\bullet$ & & - & - & & $\bullet$ & - & - & & - & - & - & \\
\hline & Ordering errors & $\bullet$ & $\bullet$ & & & $\bullet$ & $\bullet$ & $\bullet$ & $\bullet$ & $\bullet$ & $\bullet$ & & & $\bullet$ & $\bullet$ \\
\hline & Poor quality of materials & $\bullet$ & & & $\bullet$ & $\bullet$ & & & & $\bullet$ & $\bullet$ & & & $\bullet$ & $\bullet$ \\
\hline \multirow{4}{*}{ 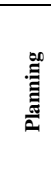 } & Wrong material storage & $\bullet$ & $\bullet$ & & $\bullet$ & & & & $\bullet$ & $\bullet$ & $\bullet$ & $\bullet$ & - & $\bullet$ & $\bullet$ \\
\hline & Poor site management & & $\bullet$ & & & - & & - & & & $\bullet$ & $\bullet$ & $\bullet$ & $\bullet$ & \\
\hline & Poor planning & $\bullet$ & & & $\bullet$ & $\bullet$ & & $\bullet$ & & & & $\bullet$ & & & \\
\hline & Lack of waste management plans & $\bullet$ & - & & & & & $\bullet$ & & & & & & & \\
\hline \multirow{5}{*}{ 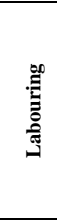 } & Workers' mistakes & $\bullet$ & - & & & $\bullet$ & & - & - & - & - & & & - & \\
\hline & Damage during transportation on site & $\bullet$ & $\bullet$ & & & $\bullet$ & $\bullet$ & & & & $\bullet$ & & $\bullet$ & $\bullet$ & \\
\hline & Lack of knowledge & & $\bullet$ & & & & $\bullet$ & & & & $\bullet$ & & & & \\
\hline & Lack of experience & & & & - & & & & & & & & & - & \\
\hline & Shortage of skilled workers & & & & $\bullet$ & & & $\bullet$ & & & & & & & \\
\hline \multirow{4}{*}{ 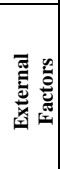 } & Effect of weather & $\bullet$ & & $\bullet$ & $\bullet$ & $\bullet$ & & $\bullet$ & & $\bullet$ & & & $\bullet$ & & \\
\hline & Accidents & $\bullet$ & & & & $\bullet$ & & $\bullet$ & & $\bullet$ & & & & & \\
\hline & Theft & $\bullet$ & $\bullet$ & & & $\bullet$ & & & & & & & & & \\
\hline & Vandalism & & $\bullet$ & & & & & & & & & & - & & \\
\hline
\end{tabular}


This matrix analysis identifies findings from past researchers around several parts of the world. Fourteen scholarly research papers were deemed significant for this study. From these papers, 24 factors that lead to waste generation on construction sites were identified. These factors are grouped into 6 categories as; design, communication, materials, planning, laboring and external factors. Table I shows the mapping of the various causes of waste against the studies that identified such wastes.

Table I shows that the factor with the highest frequency is the last-minute changes in design. This factor was identified in 13 out of the 14 articles considered in this study. This significant factor is in the category of designing which has six factors. The significant factors for all categories are shown in Table II. These six factors are the most frequent ones in literature, so they are described. However, all the other factors may also be very important in the generation of waste on construction sites as well.

Table 2. Categorization of major factors that contribute to waste generation

\begin{tabular}{ll}
\hline \hline Categorization & Major factor determined \\
\hline Designing & Last minute changes \\
\hline Comunication & Lack of coordination among parties \\
\hline Materials & Ordering errors \\
\hline Planning & Wrong material storage \\
\hline Labouring & Workers' mistakes \\
\hline External Factors & Effect of weather \\
\hline \hline
\end{tabular}

\section{A. Last Minute Changes}

The 'last minute changes' was found to be the most frequent factor that generates construction waste among other factors. These problems occur because of some of the changes requested by clients, especially in the last minute. This becomes a problem because of the inadequate communication between parties to the contract during the design stage of a building. At the design stage, the client and the designer must agree on the design and they should make the final decision together before the contractor starts the construction. If this is not done, changes may occur during the construction, when problems are encountered in the drawings.

\section{B. Lack of Coordination Among Parties}

If the parties (contractors, designers and the clients) who are involved in construction projects do not have good communication among themselves, there probably will be defects in the design. At the end, it is possible to have waste on construction sites because of the poor coordination. A good communication among team members can help avoid such wastes.

\section{Ordering Errors}

It is always important to order the materials in their right quantity to avoid delivering the materials in excess that may lead to wastage. This can be achieved through the proper estimation of materials prior to the start and during the execution of the project [26].

\section{Wrong Material Storage}

Another factor that contributes to materials wastage on site is wrong material storage which is always connected with an inappropriate protection strategy. Inadequate stacking and insufficient storage can result in waste. When materials are stacked without pallets, are wrongly stored at any open space without proper protection -such as bricks/blocks or bags of cement-, bad weather conditions -such as rain- can cause wastage of such materials. Proper storage of materials is very necessary to avoid waste generation on construction sites.

\section{E. Workers' Mistake}

Inadequate knowledge in handling materials on the part of the workers is also one of the major causes of waste on construction sites. Skoyles and Skoyles [27] highlighted the significance of human mistakes in waste minimization. According to Lingard et al. [28], for the 3Rs (i.e. reduction, reuse and recycling) to be achieved, managers should learn to work on the behavior of construction workers concerning how to handle materials. Teo et al. [29] added that the behavior of the labor forces is likely to affect the generation of waste at all levels on construction sites, hence, the need to address such issues. Tam and Tam [30], in their study revealed that when the staff were offered incentives and rewards, an estimated $23 \%$ waste reduction was recorded. As a result of that, it is important for company policies to focus on educating staff on waste reduction. The policies should also create awareness and encourage contractors to adopt waste minimization measures in their activities. The implications of such policies will be very significant to the construction industry, and help improve its performance towards sustainability [31].

\section{F. Effect of Weather}

Changes in the weather is one of the factors that cannot be controlled by human because it is a natural effect. Weather changes are caused by unforeseen circumstances. Hence, good management skills should be applied to reduce wastage that result from such occurrences [32].

\section{Construction Waste Reduction Approaches on Construction Sites}

Waste reduction is a major component in waste management. 'Waste reduction' can be defined as any activity that can reduce the quantity, supply and the environmental impact of waste. The benefits derived from waste minimization include the following [33]:

$>$ Reducing the amount of landfill spaces,

$>$ Saving natural resources,

$>$ Saving energy,

$>$ Minimizing pollution.

To achieve these benefits, there are several approaches which have been adopted worldwide. Key amongst such approaches is the use of BIM-based site management approach. Professionals within the construction sector are generally enthusiastic and propose that BIM can provide better project construction outcomes, reduced errors, 
omissions and conflicts. Although limited in literature, studies regarding the use of BIM in construction site management for construction waste prevention/reduction suggests promise and potential.

\section{Building Information Modelling}

One of the dynamic sectors where technological developments are put into practice as quickly as possible is undoubtedly the construction sector, although it is still slow compared to some sectors where industrialized production is carried out. The results of the race to follow innovations in order to make a difference in the competitive conditions of the world are followed with interest in architecture and construction world. BIM is one of the technological developments that have been increasingly seen in the recent years in the acceleration of adoption by construction project stakeholders, which are closely related to the construction industry. As the most comprehensive of the existing conditions, BIM can be thought of as a new project management concept that allows all participants to simulate all aspects of a construction project in a digital environment and share data on a single model.

\section{A. Definition of BIM}

Some of the definitions of BIM encountered in the literature survey conducted within the scope of this paper are as follows:

$>\mathrm{BIM}$ is a modeling technology that integrates all the processes (design, manufacturing, communication, analysis, etc.) involved in the life cycle of structures and inseparably interrelated [34].

$>$ BIM is a parametric component-based, threedimensional reference structure modeling system created using file formats that allow all disciplines involved in the project life cycle to exchange their data. In the broader context, BIM is a new approach to design and construction beyond modeling [35].

$>\mathrm{BIM}$ is a system that allows visualization of the entire process from the construction of a building to its physical construction [36].

$>$ Beyond being a software, technology and / or tool, BIM is the whole set of processes in which all data defining the life cycle of a building is produced and managed. The 'master builder' designation, which indicates that architects have assumed all responsibility for the structure in the ancient times, evolved as a 'master of digital architecture' for BIM in today's design and construction World [37].

$>$ BIM is a complex form of management of social and technical resources that make sense of the concepts of complexity, cooperation and interrelation, which are the most important actors of today's building world. The focus of this management system is to locate the right information at the right time and in the right place [38].

$>$ BIM is a vehicle that continues to develop rapidly in the construction sector and is used in the construction of healthy communication among all project stakeholders and continues to develop in the construction sector [39].

According to the definitions obtained as a result of the literature survey, BIM in its comprehensive form; is an interdisciplinary point of view designed to shorten the standard of the architectural and construction sector in the short term, designed to maximize the organizational scheme at the highest level, redefining the content of the project participants' definition and meeting the users' requirements at every level of the project life cycle and at every level of detail.

\section{B. Building Life Cycle and BIM Usage}

One of the most important differences of BIM's existing technologies in the design and construction sector is that it has a potential to accommodate all participants and processes involved in the project life cycle [40], not a single discipline or process. It is believed that BIM, which is thought to have an infrastructure that can be used efficiently during the predesign feasibility stage and post-construction operation and maintenance processes, is adapted to the successive progressive and chain reaction characteristics of all stages constituting the project life cycle.

It is foreseen that the area in which the technology can be used throughout the life cycle of the project must be well determined so that the value added of the BIM can meet the expectations of the employer and the contractor. In Figure 1, the project is divided into four sections as planning, design, construction and operation in the BIM utilization chart, which is produced by Penn State University Computer Integrated Research Program, interviews with leading names of the construction industry, Process, the components for which BIM can be used, the order of distribution of these components in terms of phases, and the use of BIM [41].

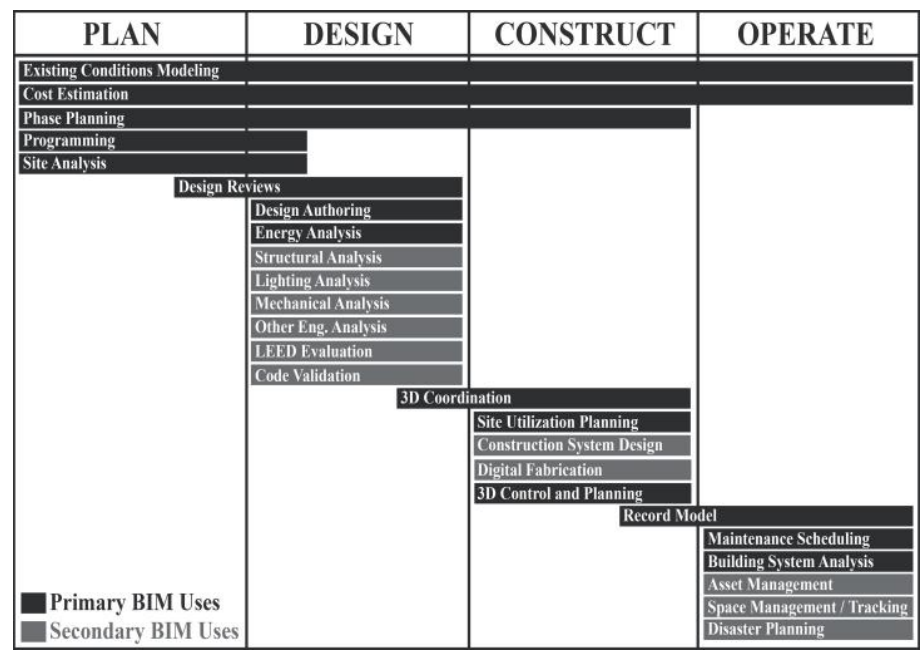

Fig. 1. Use of BIM throughout the project life cycle [41]. 


\section{Previous Researches Related to Construction Waste Prevention/Reduction by Bim-Based Construction Site}

Through a thorough review of literature, it was revealed that there are various studies that relate to BIM in construction activities but limited studies that relate to BIMbased construction site management (BCSM).

A literature searches for the last ten years -from 2007 to (February)2017- was conducted using the key words; Building Information Modeling (BIM), Construction Site Layout Planning (CSLP), Construction Site Waste Management (CSWM), Construction Waste Management (CWM), and Construction Waste Reduction (CWR). This part of the study is an integrative review that seeks to answer the following research questions:

$>$ Q1. Does BCSM help to reduce/minimize construction waste?

Q2. What features of BIM could be used to prevent/reduce construction waste on site?

Q3. What are the benefits of using BCSM to reduce construction waste?

Q4. What are the barriers to the use of BCSM to reduce construction waste?

Q5. What are the current applications of BCSM to reduce construction waste?

In all, over approximately 50 papers and texts were consulted, of which six were primary research studies [42, 43, 44, 45, 46, 47] that detailed BIM-Based Construction Site Management for C\&D Waste Prevention/Reduction. The answers to the questions asked in this section were derived from the limited studies consulted and they are discussed to include the following:

Q1. Does BCSM help to reduce/minimise construction waste?

Lu et al. [42] shared the aspect of The UK's Construction 2025 Strategy. As part of the strategy, it was revealed that "BIM has the potential to reduce/minimise construction waste during design and construction stages of projects". According to $\mathrm{Lu}$ et al. [42], many professionals in the industry, such as architects, engineers and surveyors, take this a step further by considering BIM to be a major actor in the battle against construction waste. The rhetoric tries to show the potential benefits of BIM, such as clash detection and on-site coordination. Partly owing to these potential benefits, BIM has been advocated as a solution to CWM. It provides virtual and computational environment to ponder on assorted design posibilities and construction schemes, with a view to minimizing waste before it is generated on site.

Won et al. [43] also postulated BIM as an effective means to reduce the amount of $C \& D$ waste through improving the quality and accuracy of design and construction, and minimising design errors, rework, and unexpected changes. It is a possible solution for eliminating the major causes of construction waste that arise during both the design and construction stages.
According to Cheng et al. [44], people have tried and succeeded in using BIM to reduce improper design, residues of raw materials, unexpected changes in building design and improve procurement, site planning, and material handling in construction management.

Ahankoob et al. [45] stated that a relatively new methodology which people in the construction industry are using to minimise the generation of waste in the design and pre-construction phase is the use of BIM.

Ahankoob et al. [45] and Rajendran and Gomez [46] introduced the potential use of BIM technology to minimize construction waste, but these efforts were limited to the design phase and did not discuss the specific methods to utilize BIM for C\&D waste minimization. However, the study did not propose specific methods to minimize and manage $C \& D$ waste.

Furthermore, the UK Construction 2025 Strategy recognised that BIM has the potential to reduce construction waste during design and construction stages [48]. Unfortunately, no efforts have been made to develop BIM aided CWM design decision making tools and methodologies to date. Also, there is inadequate research on the development and review of tools and methodologies that use BIM to support CWM decision making during the design phase of projects. Additionally, there are no research attempts to relate the use of BIM to construction waste causes [47].

Q2. What features of BIM could be used to prevent/reduce construction waste on site?

Lu et al. [42] described the potential benefits of BIM, such as clash detection and on-site coordination, with the assumption that they will automatically become a reality. BIM is a potential tool that can be utilized in a virtual computational environment within which designers and contractors can employ different design and construction options with a view to minimizing construction waste.

According to Won et al. [43], the uses of BIM like validation of designs, quantity take-off, phase planning, site utilization planning, amongst others were proposed for the reduction of construction waste. BIM can also enable us to minimize the amount of $\mathrm{C} \& \mathrm{D}$ waste by improving quality and accuracy of design and construction, thereby reducing design errors, rework, and unexpected changes. Use of BIM can reduce improper design, residues of raw materials, and unexpected changes in building design and improve procurement, site planning and material handling in construction management.

Ahankoob et al. [45] listed the basic BIM solutions for waste reduction to include conflict, interference and collision detection, construction sequencing and construction planning, reducing rework, synchronizing design and site layout, detection of errors and omissions (clash detection) and precise quantity take-off.

Q3. What are the benefits of using BCSM to reduce construction waste?

BIM provides a level ground for less expensive, virtual, 
graphical, and computational environment to enable stakeholders deliberate on various design options and construction schemes, which have a significant impact on construction waste minimization [42]. It is stated in $\mathrm{Lu}$ et al.'s [42, pp.589], study that "A less than well-thought-out construction scheme may cause problems in the delivery of a project, including excessive construction waste generation. BIM allows modelling of entire construction process and prior accounting of the waste-generation risks of alternative strategies. With detailed 3D models of buildings in the BIM component library, it is a 3D model of a construction project can be generated rapidly. Waste generation can be computed instantaneously and presented graphically on a dashboard along with other project performance metrics".

Consequently, validation of designs can minimize the amount of waste generated on site since such wastes are mainly generated due to improper design and unexpected changes during the design and construction phases [43]. According to Cheng et al. [44], BIM uses can also reduce different kinds of waste that can be removed by lean construction.

Q4. What are the barriers to the use of BCSM to reduce construction waste?

BIM has benefits on construction waste minimization on sites, nevertheless, as the digital representation of a physical facility, BIM itself cannot manipulate information to allow informed decision-making for CWM; and for this purpose, it relies on algorithms [42]. Lu et al. [42], Ahankoob et al. [45], Rajendran and Gomez [46] and Liu et al. [47] introduced the potential use of BIM technology to minimize construction waste, but these efforts were limited to the design phase and did not discuss the specific methods to utilize BIM for C\&D waste minimization.

Q5. What are the current applications of BCSM to reduce construction waste?

Lu et al. [42] cited Porwal and Hewage's [49] paper which they conducted a BIM-enabled analysis to minimize the waste rate of structural reinforcement. BIM was selected as the hub for communicating project information among the various design teams. The findings from the study revealed that construction waste generation can be determined at both the design and construction stages of projects, and this could be achieved by developing a system dynamics (SD) model to estimate waste generation in relation to different design and construction combinations [42].

According to Lu et al. [42, pp.589] "neither commercial BIM solutions nor academic studies have sufficiently extended BIM to perform CWM, despite widespread calls to do so". Moreover, there has not been any technique or tool available that explores BIM as a platform to reduce $C \& D$ waste [44].

\section{Conclusion}

In this study, the articles that deal with the relationship between BIM technology and construction waste management practices were examined in detail. The methods investigated the use of BIM technology related to construction waste reduction on construction sites. This study only focused on the construction process, however, design and post-production phases that are located in the project life cycle were excluded.

The common idea that emerges in all the articles examined is that BIM technology is a technological development that can be very useful in construction waste management. However, the study did not find any existing BIM based site management laid down procedures to construction waste reduction. This is mainly due to the fact that BIM is an emerging technology, and it is thought that the plug-ins to support construction waste management have not been developed yet.

It is envisaged that the construction waste that is generated consciously and / or unconsciously during the construction process can be minimized by the possibilities of technology. At this point, it is thought that BIM technology, which can create the whole project on the digital interface, can be utilized with a systemic approach.

\section{References}

[1] Waste Framework Directive 2008/98/EC, (2008). [Online].

Available: http://eurlex.europa.eu/LexUriServ/LexUriServ.do?uri=OJ:L:200 8:312:0003:0030:EN:PDF

[2] L. L. Ekanayake and G. Ofori, "Construction material source evaluation", Proceedings of the 2nd Southern African Conference on Sustainable Development in the Built Environment, Pretoria, 2000.

[3] A. Mossman, "Creating value: a sufficient way to eliminate waste in lean design and lean production", Lean Construction Journal, pp. 13-23, 2009.

[4] L. E. Chandler, Materials Management on Building Sites, England: The Construction Press Ltd., 1978.

[5] S. H. Lee, J. E. Diekmann, A. D. Songer and H. Brown, "Identifying Waste: Applications of Construction Process Analysis", Proceedings of the Seventh Annual Conference of the International Group for Lean Construction, USA, 1999.

[6] L. F. Alarcon, Training Field Personnel To Identify Waste And Improvement Opportunities In Construction, L. F. Alarcon, Ed. Lean Construction, Rotterdam: A. A. Balkema, Rotterdam, Brookfield, 1997, pp. 402-413.

[7] S. Alwi, "The Relationship Between Rework and Work Supervision of Upper Structure in The Reinforced Concrete Building Structure", M. S. Thesis, University of Indonesia, Jakarta, 1995.

[8] L. Koskela, "Lean Production in Construction", The 10th International Symposium on Automation and Robotics in Construction (ISARC), Elsevier, USA, pp. 47-54, 1993. 
[9] C. J. Robinson, Continuous Improvement in Operations; A systematic Approach to Waste Reduction, Productivity Press, Cambridge, Mass., 1991.

[10] S. Nagapan, I. A. Rahman, A. Asmi, "A Review of Construction Waste Cause Factors", Asian Conference of Real Estate: Sustainable Growth Managing Challenges (ACRE 2011), Johor Bahru, Malaysia, 2011

[11]E. R. Skoyles and E. J. Hassey, "Wastage of materials", Building Research Establishment Current Paper 44/74, 1974.

[12] A. G. Bossink and H. J. H. Brouwers, "Construction waste: quantification and source evaluation", Journal of Construction Engineering and Management, ASCE, Vol. 122(1), pp. 55-60, March 1996.

[13] L. G. Garas, R. A. Anis and E. A. Gammal, "Material Waste in the Egyptian Construction Industry", Proceedings of the 9th Annual Conference of the International Group for Lean Construction, National University of Singapore, Singapore, 2001.

[14] S. Alwi, K. Hampson and S. Mohamed, "Non ValueAdding Activities in Australian Construction Projects", In Proceedings International Conference on Advancement in Design, Construction, Construction Management and Maintenance of Building Structure, Bali, Indonesia, 2002.

[15] S. Alwi, K. Hampson and S. Mohamed, "Waste in the Indonesian construction projects", In Proceedings 1st International Conference of CIB W107 - Creating a sustainable Construction Industry in Developing Countries, South Africa, pp. 305-315, 2002.

[16]L. L. Ekanayake and G. Ofori, "Building Waste Assesment Score: Design-Based Tool", Journal of Building and Environment, Vol. 39, pp. 851-861, 2004.

[17] C. S. Poon, A. T. W. Yu and L. Jaillon, "Reducing Building Waste at Construction Sites in Hong Kong", Construction Management and Economics, Vol. 22, pp. 461-470, 2004.

[18]G. Polat and G. Ballard, "Waste in Turkish Construction: Need for Lean Construction Techniques", Proceeding 12th Annual Conference of the International Group for Lean Construction (IGLC-12), Elsinore, Denmark, pp. 488-501, 2004.

[19] C. S. Poon, A. T. W. Yu, S. W. Wong and E. Cheung, "Management of Construction Waste in Public Housing Projects in Hong Kong”, Journal of Construction Management and Economics, Vol. 22, pp. 675-689, September 2004.

[20] V. W. Y. Tam, L. Y. Shen, I. W. H. Fung and J. Y. Wang, "Controlling Construction Waste by Implementing Governmental Ordinances in Hong Kong”, Journal of Construction Innovation, Vol. 7(2), pp. 149-166, 2007.

[21] J. Y. Wang, X. P. Kang and V. W. Y. Tam, "An Investigation of Construction Wastes: An Empirical
Study in Shenzhen", Journal of Engineering, Design and Technology, Vol. 6(3), pp. 227-236, 2008.

[22] K. M. S. Wan, M. M. Kumaraswamy and D. T. C. Liu, "Contributors to Construction Debris from Electrical and Mechanical Work in Hong Kong Infrastructure Projects", Journal of Construction Engineering and Management, Vol. 135(7), 2009.

[23] A. B. Wahab and A. F. Lawal, "An evaluation of waste control measures in construction industry in Nigeria", African Journal of Environmental Science and Technology, Vol. 5(3), pp. 246-254, March 2011.

[24] W. Lu, H. Yuan, J. Li, J. J. L. Hao, W. Mi and Z. Ding, "An Empirical Investigation of Construction and Demolition Waste Generation Rates in Shenzhen City, South China", Journal of Waste Management, Vol. 31, pp. 680-687, 2011.

[25] A. A. Najafpoor, A. Zarei, F. Jamali-Behnam, M. Vahedian-Shahroudi and A. Zarei, "A Study Identifying Causes of Construction Waste Production and Applying Safety Management on Construction Site", Iranian Journal of Health Sciences, Vol. 2(3), pp. 49-54, 2014.

[26] Clackmannanshire Council, (2011). Guidance on Construction Site Waste Management. [Online]. Available:

http://www.clacksweb.org.uk/environment/constructions itewastemanagement/

[27]E. Skoyles and J. R. Skoyles, Waste prevention on site, London: Mitchell, 1987.

[28] H. Lingard, G. Gilbert and P. Graham, "Improving Solid Waste Reduction and Recycling Performance Using Goal Setting and Feedback", Construction Management and Economics, Vol. 19(8), pp. 809-817, 2001.

[29] M. M. M. Teo, M. Loosemore, M. Masosszeky and K. Karim," "Operatives Attitudes Towards Waste on a Construction Project", Annual Conference - ARCOM 2000, Vol. 2, pp. 509-517, 2000.

[30] V. Tam and C. Tam, "Waste reduction through incentives: a case study", Building Research \& Information, Vol. 36(1), pp.37-43, 2008.

[31] R. A. Begum, C. Siwar, J. J. Pereira and A. H. Jaafar, "Attitude and behavioral factors in waste management in the construction industry of Malaysia", Resources, Conservation and Recycling, Vol. 53(6), pp. 321-328, 2009.

[32] T. O. Adewuyi and I. A. Odesola, "Factors affecting material waste on construction sites in Nigeria", Journal of Engineering and Technology, Vol. 6(1), 2015.

[33] R. J. Camm and P. M. Nuttall, "Waste Minimization: Incentives and Barriers", in Waste Minimization through Process Design, A. P. Rossiter, Ed, New York: McGraw-Hill International Book Company, 1995, pp. $29-42$.

[34] C. Eastman, P. Teicholz, R. Sacks and K. Liston, BIM Handbook, 2nd Edition, New Jersey, Wiley, 2011. 
[35]R. Crotty, The Impact of Building Information Modelling: Transforming Construction, Spon Press, London, 2012.

[36]B. Hardin and D. McCool, BIM and Construction Management: Proven Tools, Methods, and Workflow, 2nd Edition, John Wiley \& Sons, 2015.

[37] R. Deutsch, BIM and Integrated Design: Strategies for Architectural Practice, John Wiley and Sons INC., New Jersey, 2011.

[38]F. E. Jernigan, Big BIM Little BIM, 4Site Press, Salisbury, Maryland, 2007.

[39]E. Krygiel and B. Nies, Green BIM: Successful Sustainable Design with Building Information Modelling, Wiley Publishing Inc., Indianapolis, Indiana, 2008.

[40]C. Bylund and A. Magnusson, Model Based Cost Estimations: An International Comparison, Lund University Faculty of Engineering, LTH, Lund, 2011.

[41]PSU, BIM operate. construct.design.plan. Project Execution Planning Guide, The Pennsylvania State University, The Computer Integrated Construction Research Group, 2010.

[42] W. Lu, C. Webster, K. Chen, X. Zhang and X. Chen, "Computational building information modelling for construction waste management: Moving from rhetoric to reality", Renewable and Sustainable Energy Reviews, Vol. 68, pp. 587-595, 2017.

[43] J. Won, J. C. P. Cheng and G. Lee, "Quantification of construction waste prevented by BIM-based design validation: Case studies in South Korea", Waste Management, Vol. 49, pp. 170-180, 2016.

[44] J. C. P. Cheng, J. Won and M. Das, "Construction and demolition waste management using BIM technology", 23rd Ann. Conf. of the International Group for Lean Construction, Perth, Australia, pp. 381-390, 29-31 July 2015.

[45] A. Ahankoob, S. M. Khoshnava, R. Rostami, C. Preece, "BIM perspectives on construction waste reduction", Management in Construction Research Association (MiCRA) Postgraduate Conference, pp. 195-199, 2012.

[46] P. Rajendran and C. P. Gomez, "Implementing BIM for Waste Minimization in the Construction Industry: A Literature Review", The 2nd International Conference on Management, Malaysia, pp. 557-570, 2012.

[47]Z. Liu, M. Osmani, P. Demian and A. Baldwin, "A BIM-aided construction waste minimisation framework", Automation in Construction, Vol. 59, pp. $1-23,2015$.

[48]HM Government, Construction 2025: Industrial Strategy: government and industry in partnership. (2013).

Available: https://www.gov.uk/government/uploads/system/uploads /attachment_data/file/210099/bis-13-955-construction2025-industrial-strategy.pdf 2013

[49] A. Porwal and K. Hewage, K., "Building Information Modeling-Based Analysis to Minimize Waste Rate of Structural Reinforcement", Journal of Construction Engineering and Management, Vol. 138(8), pp. 943-954, 2012. 